\title{
Association of MAGE A1-6 Expression with Lung Cancer Progression
}

\author{
Eunjue $\mathrm{Yi}^{1{ }^{* *}}{ }^{*}$ Ji-Eun Chang ${ }^{*}$, Chosun Leem², Chang-Ho Jeon ${ }^{3}$, and Sanghoon Jheon ${ }^{1}{ }^{\natural 凶}$ \\ 1. Department of Thoracic and Cardiovascular Surgery, Seoul National University Bundang Hospital, Seongnam-si, Gyeonggi-do, Republic of Korea; \\ 2. Respiratory Center, Seoul National University Bundang Hospital, Seongnam-si, Gyeonggi-do, Republic of Korea; \\ 3. Department of Laboratory Medicine, Catholic University of Daegu School of Medicine, Daegu, Republic of Korea; \\ 4. Department of Thoracic and Cardiovascular Surgery, Seoul National University College of Medicine, Seoul, Republic of Korea. \\ * These two authors contributed equally to this work. \\ \# Current address: Department of Thoracic and Cardiovascular Surgery, Korea University Anam Hospital, Seoul, Republic of Korea. \\ $\triangle$ Corresponding author: Sanghoon Jheon, MD, PhD, Department of Thoracic and Cardiovascular Surgery, Seoul National University Bundang Hospital, 82, \\ Gumi-ro 173beon-gil, Bundang-gu, Seongnam-si, Gyeonggi-do, 463-707, Republic of Korea. Tel: +82 31 787 2100; Fax: +82 31 787 2109; E-mail: jheon@snu.ac.kr \\ (C) Ivyspring International Publisher. This is an open access article distributed under the terms of the Creative Commons Attribution (CC BY-NC) license \\ (https://creativecommons.org/licenses/by-nc/4.0/). See http://ivyspring.com/terms for full terms and conditions.
}

Received: 2016.10.26; Accepted: 2017.03.31; Published: 2017.05.12

\begin{abstract}
The melanoma-associated antigen (MAGE) genes are known to be expressed in various kinds of tumors including lung cancer. Although they are studied as targets for immunotherapy and tools for early detection of lung cancer, the correlation between MAGE expression and the prognosis in lung cancer has not been clarified. In this study, we evaluated the relationship between MAGE A1-6 gene expression and the clinical prognosis in lung cancer.

Bone marrow aspirations were performed in 60 patients who were diagnosed as lung cancer and underwent lung cancer surgery between 2007 and 2008. Each bone marrow was examined using nested reverse transcription- polymerase chain reaction (RT-PCR) with the MAGE common primer to detect MAGE A1-6. Overall survival rate, disease-free survival rate, recurrence, and distant metastasis were reviewed retrospectively. Survival periods were analyzed using SPSS ver. 20.0.

Of the total 60 lung cancer patients, 9 patients (15\%) had MAGE A1-6. MAGE A1-6-positive patients showed poor overall survival and overall disease-free survival rates (43.8 $\pm 26.1,43.2 \pm 26.9$ months, respectively) compared with MAGE Al-6-negative patients (54.4 $\pm 17.2,44.8 \pm 22.1$ months, respectively). No significant difference was shown in either survival rates.

In conclusion, MAGE A1-6 expression of bone marrow in lung cancer patients correlated with poor survival rates. We suggest that MAGE Al-6 may be considered as a novel prognostic factor for lung cancer which leads to effective follow-up and treatment.
\end{abstract}

Key words: Lung Cancer, MAGE A1-6, Bone Marrow, Survival Rate, Recurrence, Distant Metastasis.

\section{Introduction}

Lung cancer is one of the leading causes of cancer deaths worldwide. Pulmonary surgical resection is the first-choice therapy for early stage lung cancer. However, the 5-year survival rate after complete surgical resection of stage I patients is $70 \%$ and stage III patients is only $30 \%$ [1]. To improve the outcome for lung cancer patients with surgical resection, various strategies such as adjuvant radiotherapy [2], adjuvant chemotherapy [3], and immunotherapy [4] have been suggested.
The melanoma-associated antigen (MAGE) genes are well known members of cancer/testis antigens (CTA) [5]. Since the first discovery of the MAGE family in 1991, dozens of MAGE members were identified [6]. The MAGE group is divided into two large families e.g. MAGE-I, and MAGE-II, based on functions and expression patterns [7]. The MAGE-I family includes MAGE-A, MAGE-B, and MAGE-C groups, and the MAGE-II family comprises seven subfamilies. While the MAGE-II family is expressed in 
normal tissues, the MAGE-I group, especially MAGE-A subfamily, is rarely expressed in normal tissue except for the testis, but is highly expressed in various cancer cells [8]. For this reason, MAGE-A becomes a potential biomarker for the various cancers including melanoma [9], head and neck [10], esophagus [11], bladder [12], breast [13], liver [14], and lung [15]. In addition, MAGE-A encodes tumor-specific antigens presented by human leukocyte antigen (HLA) class I molecules to $\mathrm{CD}^{+} \mathrm{T}$ lymphocytes directed against MAGE-A expressing cancer cells, therefore MAGE-I derived peptides attracted attention as targets for anticancer immunotherapy [6].

The expression of MAGE-A might be useful for not only a biomarker for immunotherapy target but also a prognosis factor which leads to effective follow-up and treatment for cancer patients. The diagnostic efficacy of MAGE-A in lung cancer has been already studied in various ways [16]. Detection of MAGE A1-6 from bronchial washing [16], sputum [17], aspirated lung tissue [18] or bone marrow [19] has been studied, and the relationship with prognosis has been suggested. In particular, MAGE A1-6 expressions are known to be related to poor survival rate for cancer patients. In this study, we evaluated the relationship between MAGE A1-6 expression and clinical prognosis in lung cancer.

\section{Materials and Methods}

\section{Patients and follow-up}

From January 2007 to June 2008, 60 patients with surgically resected lung cancer received intraoperative bone marrow biopsy at the Department of Thoracic Surgery, Seoul National University Bundang Hospital. The study population consisted of 46 male and 14 female patients and the average age at the time of surgery was $62.8 \pm 9.7$ years. The mean follow-up period was 58.9 months (range, 0.5-78.0 months). The overall survival rate, disease-free survival rate, recurrence, and distant metastasis were reviewed retrospectively.

This study was approved by the Institutional Review Board of Seoul National University Bundang Hospital (B-1104/125-004) and signed consent was obtained from all volunteers.

\section{Bone marrow preparation}

At the time of surgery, $2 \mathrm{~mL}$ of bone marrow was aspirated intraoperatively using an aspiration needle from one rib (5th or 6th rib on the anterior axillary line). The obtained bone marrow was mixed immediately with $10 \mathrm{~mL}$ of guanidine isothiocyanate buffer for ribonucleic acid (RNA) preservation and stored at $-80^{\circ} \mathrm{C}$ in a deep freezer for the analysis.

\section{MAGE A1-6 RT-nested PCR in bone marrow}

mRNA was extracted from aspirated bone marrow using mRNA extraction kits (iC\&G Co., Daegu, South Korea), as in the previous studies [16, 17]. RNA purity and concentration were measured by spectrophotometer (DU 530, Beckman Instruments Inc., Fullerton, CA, USA). MAGE A1-6 common primer was used for nested reverse transcriptionpolymerase chain reaction (RT-PCR) to maximize detection [20]. MAGE A1-6 and glyceraldehyde-3-phosphate dehydrogenase (GAPDH) genes were amplified with Cancer-Hunter ${ }^{\circledR}$ Kits (iC\&G Co.). We used DNA bases standardized at $469-490$ bp as markers to compare the molecular weight of the MAGE A1-6 genes. The samples were identified whether MAGE A1-6-positive or negative by comparing the bands corresponding to the marker. If there was a band corresponding to the marker band, the sample was determined to be MAGE A1-6-positive. On the other hand, if no band was shown corresponding to the marker band, the sample was determined to be MAGE A1-6-negative.

\section{Statistical analysis}

The $x$ 2-test was used to compare the overall and disease-free survival periods between MAGE A1-6-positive patients and MAGE A1-6-negative patients. Kaplan-Meier survival analysis was also used. Analysis was performed using SPSS ver. 20.0 (Statistical Package for the Social Sciences, Chicago, IL, USA). A statistically significant difference was considered present when the two-tailed $p$-values were less than 0.05 .

\section{Results}

\section{Patient characteristics}

The characteristics of enrolled patients in this study are described in Table 1.9 of the $60(15 \%)$ patients were MAGE A1-6-positive and 51 of the 60 $(85 \%)$ were MAGE A1-6-negative. The stage breakdown was 0 in 1 of the $60(1.7 \%)$ patients, IA in 16 of the $60(26.7 \%)$ patients, IB in 17 of the $60(28.3 \%)$ patients, IIA in 11 of the $60(18.3 \%)$ patients, IIB in 3 of the $60(5 \%)$ patients, IIIA in 7 of the $60(11.7 \%)$ patients, IIIB in 2 of the $60(3.3 \%)$ patients, and IV in 3 of the 60 patients $(5 \%)$. The operation types were 1 of the 60 case of wedge resection (1.7\%), 45 of the 60 cases of lobectomy (75\%), 4 of the 60 cases of bilobectomy $(6.7 \%), 7$ of the 60 cases of sleeve lobectomy $(11.7 \%)$, and 3 of the 60 cases of pneumonectomy $(5 \%)$. The histopathologies of lung cancers were squamous cell carcinoma in 27 of the 60 patients $(45 \%)$, adenocarcinoma in 27 of the 60 patients $(45 \%)$, and others in 6 of the 60 patients $(10 \%)$. 
Table 1. Correlation between MAGE A1-6 expression and clinicopathologic data in 60 lung cancer patients.

\begin{tabular}{|c|c|c|c|c|}
\hline Variables & $\begin{array}{l}\text { Total } \\
\text { n (\%) }\end{array}$ & $\begin{array}{c}\text { MAGE A1-6 (+) } \\
\text { n (\%) }\end{array}$ & $\begin{array}{c}\text { MAGE A1-6 (-) } \\
\text { n (\%) }\end{array}$ & $p$-value \\
\hline Numbers & $60(100 \%)$ & $9(15 \%)$ & $51(85 \%)$ & \\
\hline Sex & & & & 0.322 \\
\hline Male & $46(76.7 \%)$ & $8(13.3 \%)$ & $38(63.3 \%)$ & \\
\hline Female & $14(23.3 \%)$ & $1(1.7 \%)$ & $13(21.7 \%)$ & \\
\hline Age (years) & $62.8 \pm 9.7$ & $62.6 \pm 9.9$ & $63.9 \pm 9.2$ & 0.711 \\
\hline Stage & & & & 0.744 \\
\hline 0 & $1(1.7 \%)$ & $0(0 \%)$ & $1(1.7 \%)$ & \\
\hline IA & $16(26.7 \%)$ & $4(6.7 \%)$ & $12(20 \%)$ & \\
\hline IB & $17(28.3 \%)$ & $1(1.7 \%)$ & $16(26.7 \%)$ & \\
\hline IIA & $11(18.3 \%)$ & $2(3.3 \%)$ & $9(15.5 \%)$ & \\
\hline IIB & $3(5 \%)$ & $1(1.7 \%)$ & $2(3.3 \%)$ & \\
\hline IIIA & $7(11.7 \%)$ & $1(1.7 \%)$ & $6(10 \%)$ & \\
\hline IIIB & $2(3.3 \%)$ & $0(0 \%)$ & $2(3.3 \%)$ & \\
\hline IV & $3(5 \%)$ & $0(0 \%)$ & $3(5 \%)$ & \\
\hline Operation & & & & 0.023 \\
\hline Wedge & $1(1.7 \%)$ & $1(1.7 \%)$ & $0(0 \%)$ & \\
\hline Lobectomy & $45(75 \%)$ & $6(10 \%)$ & $39(65 \%)$ & \\
\hline Bilobectomy & $4(6.7 \%)$ & $2(3.3 \%)$ & $2(3.3 \%)$ & \\
\hline Sleeve lobectomy & $7(11.7 \%)$ & $0(0 \%)$ & $7(11.7 \%)$ & \\
\hline Pneumonectomy & $3(5 \%)$ & $0(0 \%)$ & $3(5 \%)$ & \\
\hline Histology & & & & 0.993 \\
\hline Squamous & $27(45 \%)$ & $4(6.7 \%)$ & $23(38.3 \%)$ & \\
\hline Adenocarcinoma & $27(45 \%)$ & $4(6.7 \%)$ & $23(38.3 \%)$ & \\
\hline Others & $6(10 \%)$ & $1(1.7 \%)$ & $5(8.3 \%)$ & \\
\hline
\end{tabular}

Table 2. Correlation between MAGE Al-6 expression and survival periods without/with recurrence or distant metastasis.

\begin{tabular}{|c|c|c|c|c|}
\hline Survival periods & & $\begin{array}{c}\text { MAGE A1-6 (+) } \\
\text { average } \pm \text { SD } \\
\text { (months) }\end{array}$ & $\begin{array}{c}\text { MAGE A1-6 (-) } \\
\text { average } \pm \text { SD } \\
\text { (months) }\end{array}$ & $p$-value \\
\hline \multicolumn{5}{|l|}{ Total patients } \\
\hline & Overall survival periods & $43.8 \pm 26.1$ & $54.4 \pm 17.2$ & 0.268 \\
\hline & Overall disease-free survival periods & $43.2 \pm 26.9$ & $44.8 \pm 22.1$ & 0.868 \\
\hline \multicolumn{5}{|c|}{ Without recurrence } \\
\hline & Overall survival periods & $47.3 \pm 25.5$ & $58.3 \pm 10.1$ & 0.268 \\
\hline \multicolumn{5}{|l|}{ With recurrence } \\
\hline & Overall survival periods & 15.9 & $47.4 \pm 24.5$ & \\
\hline & Overall disease-free survival periods & 10.0 & $20.1 \pm 15.6$ & \\
\hline \multicolumn{5}{|c|}{ Without distant metastasis } \\
\hline & Overall survival periods & $43.8 \pm 26.1$ & $57.0 \pm 15.0$ & 0.175 \\
\hline & Overall disease-free survival periods & $43.2 \pm 26.9$ & $52.1 \pm 17.3$ & 0.364 \\
\hline \multicolumn{5}{|c|}{ With distant metastasis } \\
\hline & Overall survival periods & & $44.9 \pm 21.8$ & \\
\hline & Overall disease-free survival periods & & $18.2 \pm 16.8$ & \\
\hline
\end{tabular}

\section{Survival analysis}

The correlation between MAGE A1-6 expression and survival periods are shown in Figure 1 and Table 2. The average overall survival periods were $43.8 \pm$ 26.1 months for MAGE A1-6-positive patients and $54.4 \pm 17.2$ months for MAGE A1-6-negative patients. The mean overall survival periods of MAGE A1-6-positive patients were relatively lower than those of patients with negative MAGE A1-6, but there was no significant difference between the two groups in overall survival periods $(p=0.268)$.

The average overall disease-free survival periods of MAGE A1-6-positive patients were $43.2 \pm 26.9$ months while those of MAGE A1-6-negative patients were $44.8 \pm 22.1$ months. There was also no significant difference between the two groups $(p=0.868)$.

\section{Relevance with recurrence and distant metastasis}

Of the 51 patients who showed no MAGE A1- 6 expressions, 18 of the 19 patients (94.7\%) had loco-regional recurrence, and 11 of the 11 patients $(100 \%)$ had distant metastasis. In the 9 patients with MAGE A1-6 expression, only 1 of the 19 patient (5.3\%) 
showed loco-regional recurrence, and no patient had distant metastasis (Table 3).

In groups without recurrence, overall survival periods of MAGE A1-6-positive patients were $47.3 \pm$ 25.5 months and those of MAGE A1-6-negative patients were $58.3 \pm 10.1$ months. The overall survival periods without recurrence of MAGE A1-6-positive patients was lower than that of MAGE A1-6-negative patients, but no significant difference was found $(p=0.268)$.

Patients with recurrence, overall survival periods and disease-free survival periods of patients with MAGE A1-6 were 15.9 and 10.0 months, respectively. Those of patients without MAGE A1-6 were $47.4 \pm 24.5$ and $20.1 \pm 15.6$ months, respectively.

In groups without distant metastasis, overall survival periods and disease-free survival periods of MAGE A1-6-positive patients $(43.8 \pm 26.1$ and $43.2 \pm$ 26.9 months) were lower than those of MAGE A1-6-negative patients $(57.0 \pm 15.0$ and $52.1 \pm 17.3$ months) but without statistical significance. $P$-values were 0.175 and 0.364 , respectively.

With distant metastasis, overall survival periods and disease-free survival periods of MAGE A1-6-negative patients were $44.9 \pm 21.8$ and $18.2 \pm 16.8$ months, respectively (Table 2).

\section{Discussion}

Many researchers demonstrated MAGE-A gene expression in various cancers to develop a novel

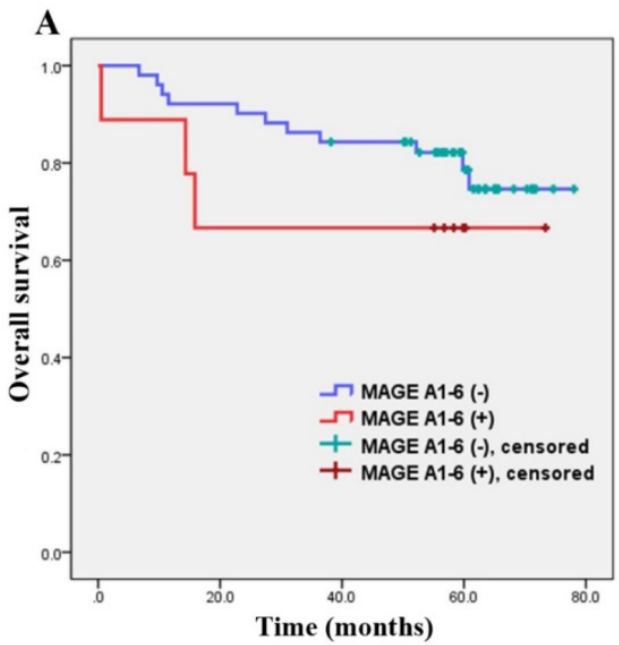

cancer detection tool and an effective immunotherapy target. However, only a few studies reported the correlation between MAGE gene expression and oncologic outcomes. Ogata et al. suggested that MAGE A1 expression can be a predictive maker of poor prognosis in differentiated advanced gastric cancer [21]. Gu et al. demonstrated that MAGE A9 expression suggests unfavorable survival outcome in hepatocellular carcinoma [22]. Lian et al. reported that MAGE A10-11 expression is a potential poor prognostic factor for breast cancer [23], and Noh et al. elucidated that MAGE A1-6 expression in patients with head and neck is correlated with poor oncologic outcomes [24]. In those previous studies, MAGE-A subfamily has been proved to be an unfavorable prognostic factor in various cancers.

Detection of MAGE-A group in bronchial lavage fluid, sputum or aspirated lung tissues from lung cancer patients was reported to be a feasible method for lung cancer diagnosis, although in practice it has not yet been commonly utilized. The relationship between MAGE-A and lung cancer prognosis has not been studied actively. There is a paucity of studies of lung cancer prognosis related to the expression of MAGE-A group. In this study, we set out to determine whether MAGE A1-6 had any relationship with lung cancer prognosis such as overall or disease-free survival rate, recurrence, and distant metastasis.

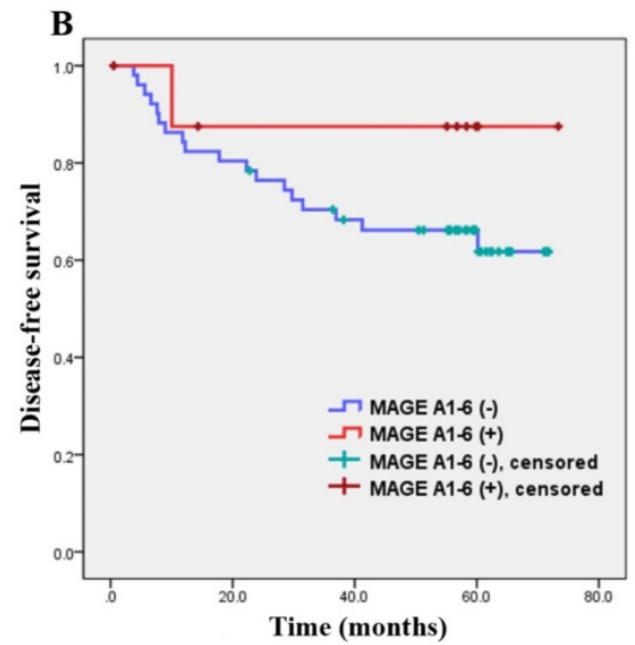

Figure 1. Overall survival curve (A) and disease-free survival curve (B). There were no significant differences between MAGE A1-6(-) patients and MAGE A1-6(+) patients in overall survival and disease-free survival periods.

Table 3. Correlation of MAGE Al-6 expression with recurrence and distant metastasis.

\begin{tabular}{lcccc}
\hline \multicolumn{1}{c}{ Variables } & Total & MAGE A1-6(+) & MAGE A1-6(-) & $p$-value \\
& $\mathrm{n}(\%)$ & $\mathrm{n}(\%)$ & $\mathrm{n}(\%)$ & \\
\hline Recurrence & $19(100 \%)$ & $1(5.3 \%)$ & $18(94.7 \%)$ & 0.147 \\
Distant metastasis & $11(100 \%)$ & $0(0 \%)$ & $11(100 \%)$ & 0.405 \\
\hline
\end{tabular}


Most investigators used microarray analysis [25], RT-PCR [26], and RNA in situ hybridization [27] for detection of MAGE expression. We applied nested RT-PCR using a MAGE A1-6 common primer, which can detect all MAGE A1-6 subtypes. Since the expression level of individual subtype of MAGE was too low to detect, MAGE A1-6 common primer was designed to increase MAGE detection by binding to the complementary deoxyribonucleic acid (cDNA) sequences of MAGE- $1,-2,-3,-4 a,-4 b,-5 a,-5 b$ and- 6 (MAGE 1-6) together [20]. This technique was already proved to detect MAGE genes effectively in colorectal [28], head and neck [29], thyroid [30], and lung [31] cancers.

Though there was no significant difference between MAGE A1-6-positive patients and negative patients, lung cancer patients with MAGE A1-6 showed poor overall survival and overall disease-free survival (43.8 $\pm 26.1,43.2 \pm 26.9$ months, respectively) compared with lung cancer patients without MAGE A1-6 (54.4 $\pm 17.2,44.8 \pm 22.1$ months, respectively). This finding indicates that MAGE-A expression in lung cancer patients predicts a poor outcome furthermore, it was in accordance with the previous published data [21-24].

MAGE A1-6-negative patients showed an unfavorable prognosis in local recurrence and distant metastasis. Since only 9 patients were MAGE A1-6 positive, among them, local recurrence occurred in only 1 patient and distant metastasis in none. For this reason, comparing MAGE A1-6-positive and negative patients with local recurrence and distant metastasis factors were meaningless in this study.

This study has some limitations. First, only 60 patients were enrolled in the study. Since high technique was needed for bone marrow aspiration from the rib, only a small number of patients were enrolled. Furthermore, only 9 of 60 patients $(15 \%)$ showed MAGE A1-6-positive and it might lead to statistical bias. For further study, we are planning to extend the study period to increase the study population. Secondly, we performed univariate analysis only, because of the small number of MAGE A1-6-positive patients.

MAGE-A groups were thought to be attractive candidates for evaluating cancer diagnosis and treatment. They were also studied as factors indicated of cancer recurrence. Although recent studies achieved great progression in knowledge regarding MAGE families, much of their functions still remain wrapped in enigma. MAGE should be further investigated not only concerning the territory of their pathologic mechanisms, but also in terms of their clinical applications. Our study could represent a tiny step forward to this giant work. We suggest that the correlation between MAGE A1-6 gene expression in bone marrow and lung tissue, bronchial washing or sputum from the same lung cancer patient should be determined for the future study.

\section{Conclusions}

MAGE A1-6 expression of bone marrow in lung cancer patients was correlated with poor prognosis in survival rate. Although a large number of patients should be enrolled in the further study, MAGE A1-6 should be considered as a promising biomarker to determine further follow-up and treatment for lung cancer patients.

\section{Acknowledgements}

The authors are indebted to J. Patrick Barron, Professor Emeritus, Tokyo Medical University and Adjunct Professor, Seoul National University Bundang Hospital for his pro bono editing of this manuscript.

\section{Competing Interests}

The authors have declared that no competing interest exists.

\section{References}

1. Dominioni L, Imperatori A, Rovera F, Ochetti A, Torrigiotti G, Paolucci M. Stage I nonsmall cell lung carcinoma. Cancer. 2000; 89: 2334-44.

2. Trodella L, Granone P, Valente S, Valentini V, Balducci M, Mantini G, et al. Adjuvant radiotherapy in non-small cell lung cancer with pathological stage I: definitive results of a phase III randomized trial. Radiother Oncol. 2002; 62: 11-9.

3. Arriagada R, Bergman B, Dunant A, Le Chevalier T, Pignon JP, Vansteenkiste $\mathrm{J}$, et al. Cisplatin-based adjuvant chemotherapy in patients with completely resected non-small-cell lung cancer. The New England journal of medicine. 2004; 350: 351-60.

4. Anagnostou VK, Brahmer JR. Cancer immunotherapy: a future paradigm shift in the treatment of non-small cell lung cancer. Clin Cancer Res. 2015; 21: 976-84.

5. Simpson AJ, Caballero OL, Jungbluth A, Chen Y-T, Old LJ. Cancer/testis antigens, gametogenesis and cancer. Nature Reviews Cancer. 2005; 5: 615-25.

6. Sang M, Wang L, Ding $C$, Zhou $X$, Wang $B$, Wang L, et al. Melanoma-associated antigen genes-An update. Cancer Lett. 2011; 302: 85-90.

7. Monte M, Simonatto M, Peche LY, Bublik DR, Gobessi S, Pierotti MA, et al. MAGE-A tumor antigens target p53 transactivation function through histone deacetylase recruitment and confer resistance to chemotherapeutic agents. Proceedings of the National Academy of Sciences. 2006; 103: 11160-5.

8. Weynants P, Lethé B, Brasseur F, Marchand M, Boon T. Expression of mage genes by non-small-cell lung carcinomas. Int J Cancer. 1994; 56: 826-9.

9. Van Der Bruggen P, Zhang Y, Chaux P, Stroobant V, Panichelli C, Schultz ES, et al. Tumor-specific shared antigenic peptides recognized by human $\mathrm{T}$ cells. Immunological reviews. 2002; 188: 51-64.

10. Lee KD, Chang HK, Jo YK, Kim BS, Lee BH, Lee YW, et al. Expression of the MAGE 3 gene product in squamous cell carcinomas of the head and neck. Anticancer Res. 1999; 19: 5037-42.

11. Inoue H, Mori M, Li J, Mimori K, Honda M, Nakashima H, et al. Human esophageal carcinomas frequently express the tumor-rejection antigens of MAGE genes. Int J Cancer. 1995; 63: 523-6.

12. Yin B, Liu G, Wang XS, Zhang H, Song YS, Wu B. Expression profile of cancer-testis genes in transitional cell carcinoma of the bladder. Urologic oncology. 2012; 30: 886-92.

13. Fujie T, Mori M, Ueo H, Sugimachi K, Akiyoshi T. Expression of MAGE and BAGE genes in Japanese breast cancers. Annals of oncology : official journal of the European Society for Medical Oncology. 1997; 8: 369-72.

14. Yamashita N, Ishibashi H, Hayashida K, Kudo J, Takenaka K, Itoh K, et al. High frequency of the MAGE-1 gene expression in hepatocellular carcinoma. Hepatology. 1996; 24: 1437-40. 
Journal of Cancer 2017, Vol. 8

1329

15. Sienel W, Varwerk C, Linger A, Kaiser D, Teschner M, Delire M, et al. Melanoma associated antigen (MAGE)-A3 expression in Stages I and II non-small cell lung cancer: results of a multi-center study. European journal of cardio-thoracic surgery : official journal of the European Association for Cardio-thoracic Surgery. 2004; 25: 131-4.

16. Kim HR, Kim TH, Chung J-H, Yon HI, Lee CT, Rang CH, et al. The detection of peripheral lung cancer by MAGE A1-6 RT-nested PCR in bronchial washing specimens. Lung Cancer. 2009; 65: 166-9.

17. Jheon S, Hymn D-S, Lee S-C, Mon G-S, Jon C-H, Park J-W, et al. Lung cancer detection by a RT-nested PCR using MAGE A1-6 common primers. Lung Cancer. 2004; 43: 29-37.

18. Thai J-R, Ching I-W, Chen Y-H, Yang M-J, Shew C-C, Chang H-C, et al. Differential expression profile of MAGE family in non-small-cell lung cancer. Lung Cancer. 2007; 56: 185-92.

19. Sienel W, Mecklenburg I, Dango S, Ehrhardt P, Kirschbaum A, Passlick B, et al. Detection of MAGE-A Transcripts in Bone Marrow Is an Independent Prognostic Factor in Operable Non-Small-Cell Lung Cancer. Chin Cancer Res. 2007; 13: 3840-7.

20. Park J-W, Kwon TK, Kim I-H, Son S-S, Kim Y-S, Kim C-I, et al. A new strategy for the diagnosis of MAGE-expressing cancers. Journal of immunological methods. 2002; 266: 79-86.

21. Ogata K, Adhara R, Mochiki E, Ogawa A, Yanai M, Toyomasu Y, et al. Clinical significance of melanoma antigen-encoding gene-1 (MAGE-1) expression and its correlation with poor prognosis in differentiated advanced gastric cancer. Annals of surgical oncology. 2011; 18: 1195-203.

22. Gu X, Eu M, Ge Z, Khan F, Ding Y, Ni H, et al. High expression of MAGE-A9 correlates with unfavorable survival in hepatocellular carcinoma. Scientific reports. 2014; 4: 6625 .

23. Dian Y, Sang M, Ding C, Chou X, Fan X, Xu Y, et al. Expressions of MAGE-A10 and MAGE-A11 in breast cancers and their prognostic significance: a retrospective clinical study. Journal of cancer research and clinical oncology. 2012; 138: 519-27.

24. No ST, Lee HS, Rim SJ, Kim SW, Chang HK, Oh J, et al. MAGE-A1-6 expression in patients with head and neck squamous cell carcinoma: impact on clinical patterns and oncologic outcomes. International journal of clinical oncology. 2016; 21: 875-82.

25. Zammatteo N, Lockman L, Brasseur F, De Plain E, Lurquin C, Lobert P-E, et al. DNA microarray to monitor the expression of MAGE-A genes. Clinical chemistry. 2002; 48: 25-34.

26. Chomez P, De Backer O, Bertrand M, De Plain E, Boon T, Lucas S. An overview of the MAGE gene family with the identification of all human members of the family. Cancer Res. 2001; 61: 5544-51.

27. Nishimura I, Shimizu S, Sakoda J-y, Yoshikawa K. Expression of Drosophila MAGE gene encoding a necdin homologous protein in postembryonic neurogenesis. Gene Expression Patterns. 2007; 7: 244-51.

28. Park MS, Park JW, Jon CH, Lee KD, Chang HK. Expression of melanoma antigen-encoding genes (MAGE) by common primers for MAGE-A1 to -A6 in colorectal carcinomas among Koreans. Journal of Korean medical science. 2002; 17: 497-501.

29. Lee KD, Lee HH, Jor HB, Lee HS, Mu TH, Chang HK, et al. Expression of MAGE A 1-6 mRNA in sputa of head and neck cancer patients--a preliminary report. Anticancer Res. 2006; 26: 1513-8.

30. Lee HS, Kim SW, Hong JC, Jung SB, Jon CH, Park JW, et al. Expression of MAGE A1-6 and the clinical characteristics of papillary thyroid carcinoma. Anticancer Res. 2013; 33: 1731-5.

31. Jheon S, Hymn DS, Lee SC, Mon GS, Jeon CH, Park JW, et al. Lung cancer detection by a RT-nested PCR using MAGE A1--6 common primers. Lung Cancer. 2004; 43: 29-37.

http://www.jcancer.org 